\title{
WAKAF UANG TERHADAP PROGRAM PENGENTASAN KEMISKINAN DI KOTA METRO
}

\author{
TRI WAHYUNI, M.H \\ (Dosen IAI Agus Salim Metro)
}

\begin{abstract}
In the provisions of the law there are two models of money waqf, namely waqf money for a certain period of time and endowments of money forever. A certain period of money waqf must be invested in banking products to make it safer and easier for the waqf party to receive the money back at maturity. While endowments of money are forever, nazir has full authority to manage and develop waqf money to achieve the goals of their waqf. If investment activities use waqf collection funds, then for the net business profits of this investment (ie gross income minus operating costs), it will be distributed in accordance with the provisions of the waqf law, namely $90 \%$ of the profits will be intended for endowments (mauquf 'alaih) and 10\% for manager or offline receipts. The managed money waqf can have a multiplier effect on the economy of Metro City, both the results of waqf investment are given in the form of economic sector assistance and non-economic sectors. These results will directly and indirectly be able to provide a significant influence in alleviating poverty. The Metro Waqf Movement is a voluntary movement that invites all campus residents to move together. Cash Waqf is a waqf mechanism for building the endowment of the ummah. By representing once but reward without stopping. In contrast to alms which are once used up, cash waqf can be developed into business units and the results are for the benefit of the ummah. So far, cash waqf has been carried out by IAIN Metro lecturers and employees voluntarily. We do cash waqf by setting aside monthly salary according to willingness. We are optimistic that this voluntary movement will increasingly invite other people to get involved without coercion. For this reason, socialization of waqf money must be continuously campaigned by all parties, especially on the Agus Salim Metro IAI Campus.
\end{abstract}




\section{A. PENDAHULUAN}

Hukum Islam yang berlaku bagi para pemeluk Islam (muslim), sumber hukumnya berasal dari nash (Al-Qur"an dan Al-Hadits). Khusus untuk melaksanakan ajaran Islam yang berdimensi sosial ekonomi (muamalah) memerlukan pemahaman dan penelitian lebih lanjut, karena aspek muamalah lebih bersifat dinamis dan lentur dalam pengembangan dan penerapan hukumnya daripada ajaran Islam yang berdimensi ibadah. Karenanya nash dalam tataran muamalah adalah "janganlah diharamkan

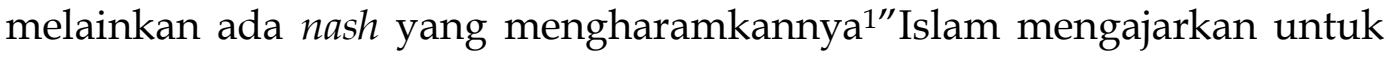
melakukan kebajikan terhadap sesama anggota masyarakat salah satunya dalam bentuk harta. Islam mengajarkan untuk memberikan harta terbaik yang dimiliki untuk kepentingan publik. Dalam hal ini, Al-Qur" an menyebutnya sebagai al-habs sinonim dari kata al-waqaf, yaitu harta benda milik person yang diberikan untuk publik agar dapat dimanfaatkan selama barang itu tetap ada. Maka, esensi wakaf terletak pada wujud barangnya yang dalam ajaran Islam sebagai amal jariah yang bersifat terus-menerus.

Saat ini telah terjadi perubahan yang signifikan atas pemahaman dan pemberdayaan harta wakaf di masyarakat, pada awalnya praktek wakaf lebih banyak dikembangkan pada sarana ibadah, sarana pendidikan, sarana kesehatan, dan manfaat sosial lainnya menjadi suatu wakaf produktif termasuk salah satunya dalam bentuk wakaf uang. Perluasan dari pemahaman dan pemberdayaan harta wakaf menjadi suatu hal yang penting terutama jika dikaitkan dengan konsep pengembangan wakaf produktif yang bertujuan untuk kepentingan sosial kemasyarakatan. Wakaf produktif memiliki dua visi sekaligus²: menghancurkan struktur-struktur sosial yang timpang dan menyediakan lahan subur untuk mensejahterakan umat Islam. Visi ini secara langsung digapai ketika totalitas diabdikan untuk bentuk-bentuk wakaf produktif yang selanjutnya diteruskan dengan langkah-langkah taktis yang mengarah pada capaian tersebut. Langkah taktis, sebagai derivasi dari filosofi disyariatkannya wakaf produktif dimana lebih berupaya teknisteknis pelaksanaan wakaf produktif.

Penerapan wakaf uang sebagai salah satu bentuk wakaf produktif pada masa sekarang akan mempunyai keunggulan yang lebih besar dari wakaf tradisional, yaitu benda bergerak atau tidak bergerak. Identik di masyarakat apabila dikatakan harta wakaf, maka akan langsung

1 M. Hasbi Ash Shiddieqy, 1998, Falsafah Hukum Islam, Cet ke-3 Bulan Bintang, Jakarta, Hal 77

${ }^{2}$ Abdurrahman Kasdi, ,Pemberdayaan Wakaf Produktif Untuk Keadilan Sosial dan Kesejahteraan Umat (Optimalisasi Potensi Wakaf Produktif di Indonesia)', Jurnal Asy-Syir'ah, Vol. 44, No. II, (2010): 796. 
dihubungkan dengan sekolah, rumah sakit dan atau kuburan. Secara umum, wakaf benda bergerak atau tidak bergerak hanya dapat dilakukan oleh orang yang memiliki harta lebih. Hal inilah yang menyebabkan kekayaan wakaf di Indonesia masih sedikit. Selain karena jumlah harta wakaf yang masih sedikit, pengelolaannya pun masih belum menerapkan manajemen modern. Sedangkan wakaf uang dapat dilakukan banyak orang, meskipun tidak kaya. Seseorang dapat berwakaf uang sebesar Rp. $100.000,-$.

Wakaf uang tersebut dapat dihimpun dalam sebuah wadah, sehingga menjadi modal usaha yang besar. Dana wakaf uang yang terkumpul tersebut dapat dikelola secara produktif dengan lembaga pengelola yang memiliki kompetensi dan kapabilitas serta mampu bekerja secara profesional. Pengoptimalan sumber-sumber keuangan Islam termasuk wakaf uang sebagai salah satu sub-sistem yang dapat mendukung program pemberdayaan masyarakat yang dilaksanakan oleh pemerintah terkait dengan pengentasan permasalahan kemiskinan yang terdapat di masyarakat terutama di negara berkembang seperti Indonesia.

Dukungan dari sub-sistem selain pemerintah sangat dibutuhkan agar manfaat pemberdayaan masyarakat dapat semakin berdayaguna dalam meningkatkan kemaslahatan masyarakat, karena seluruh program pengentasan kemiskinan yang telah dilaksanakan oleh pemerintah dengan tujuan untuk memberdayakan masyarakat masih belum mampu memperlihatkan hasil yang signifikan di masyarakat. Hal ini menandakan bahwa program pemberdayaan masyarakat masih membutuhkan dukungan dari sub-sistem lain. Melalui IAIN Metro, Gerakan Metro Wakaf melakukan sosialisasi ke mahasiswa baru. Gerakan Metro Wakaf dipimpin langsung oleh Wakil Rektor I IAIN Metro Dr. Suhairi, S.Ag, MH dengan melibatkan UKM KSEI Filantropi, Jurai Siwo Corner dan BMT AtTaawun. Gerakan Metro Wakaf adalah gerakan sukarela yang mengajak semua warga kampus untuk bergerak bersama. Wakaf Tunai adalah mekanisme wakaf untuk membangun dana abadi ummat. Dengan berwakaf sekali tapi pahala tanpa henti. Berbeda dengan sedekah yang sekali habis, wakaf tunai dapat dikembangkan ke unit usaha dan hasilnya untuk kepentingan ummat. Negara tetangga yang sudah mengambangkan wakaf tunai secara professional yaitu Malaysia dan Singapura. Dr. Suhairi, S.Ag.,MH menyampaikan kepada redaksi metrouniv.ac.id,"Selama ini wakaf tunai sudah dilakukan oleh dosen dan karyawan secara sukarela. Kami melakukan wakaf tunai dengan menyisihkan uang gaji bulanan sesuai kerelaan. Kami optimis bahwa gerakan sukarela ini akan semakin banyak mengajak orang lain untuk 
terlibat tanpa paksaan. Untuk itu sosialisasi wakaf uang harus terus dikampanyekan oleh semua pihak." 3

\section{B. PENGERTIAN WAKAF}

Wakaf berasal dari bahasa arab al-waqfu bentuk masdar (kata dasar) dari kalimat وقف- يقف- وقفا , kata al-waqfu bentuk jamaknya ialah wuquf atau auqaf yang artinya semakna dengan al-habs bentuk masdar dari حبس- يحبس - حبسا yang mempunyai arti menahan.

Secara etimologi, wakaf adalah al-habs (menahan). Sedangkan secara terminologi, yaitu: menahan suatu barang yang ditentukan, menerima untuk dipindahkan, mungkin untuk di ambil manfa'atnya besertaan tetapnya barang dan putusnya mengunakan barang tersebut akan tetapi dipergunakan dijalan kebaikan yang bertujuan untuk mendekatkan diri kepada Allah.Imam Taqiyuddin abi Bakr lebih menekankan pada batasannya, batasan waqaf menurut sara' yaitu menahan harta yang mungkin untuk diambil manfaatnya besertaan tetapnya barang tersebut dilarang untuk menggunakannya (Tasarruf) dan diperbolehkan menggunakannya (Tasarruf) untuk kebaikan yaitu mendekatkan diri kepada Allah.Al-Kazimy al-Kazwiny mendefinisikan wakaf adalah menahan suatu benda ('ain) dan menjalankan manfaatnya, dengan menngunakan kata "aku mewakafkan" atau "aku menahan" atau kata sepadannya.

Dari baberapa definisi diatas, mengindikasikan sifat abadi wakaf atau dengan kata lain, istilah wakaf diterapkan untuk harta yang tidak musnah dan manfaatnya dapat diambil tanpa mengonsumsi harta benda itu sendiri. Oleh karenanya wakaf indentik dengan tanah, kuburan, masjid, langgar, meskipun adapula wakaf buku-buku, mesin pertaian, binatang ternak, saham dan aset, serta uang tunai (wakaf tunai/cash wakaf)dapat. Dengan demikian, secara garis besar wakaf dapat dibagi dalam dua kategori Pertama, direct wakaf dimana aset yang ditahan/diwakafkan dapat mengahsilkan manfaat/jasa yang kemudian dapat digunakan oleh orang banyak (beneficiaries) seperti rumah, ibadah, sekolah dan lain lain. Kedua, wakaf investasi (aset yang diwakafkan digunakan untuk investasi). Wakaf aset ini dikembangkan untuk menghasilkan produk atau jasa yang dapat dijual untuk menghasilkan pendapatan, dimana pendapatan tersebut kemudian digunakan untuk membangun fasilitas-fasilitas umum masjid, pusat kegiatan umat islam dan lain-lain.

${ }^{3}$ metrouniv.ac.id, IAIN Metro Lampung 
Dari ulama' Hanafiyyah, Imam Sarkhosi mendefinisikan wakaf yang bersumber dari Abu Hanifah : Menahan harta dari jangkauan (kepemilikan) orang lain. Menurut Ulama Malikiyyah, Ibnu Arafah, bahwa wakaf adalah memberikan manfaat sesuatu, pada batas waktu keberadaannya, bersamaan tetapnya wakaf dalam kepemilikan pemberinya meski hanya perkiraan.

Sedangkan menurut Ulama Hanabilah, Ibnu qudamah mendefinisikan, bahwa wakaf adalah: menahan yang asal dan memberikan manfaatnya.Ulama Syafi'iyah menerangkan bahwa wakaf adalah penahanan dari bertasarruf dan mensedakahkan hasilnya serta berpindahnya pemilikan dari orang yang berwakaf kepada orang yang menerima wakaf dan tidak boleh bertindak sekehendak hati mauquf alaih.Rumusan yang termuat dalam Kompilasi Hukum Islam, dimana disebutkan dalam pasal 215 ayat (1) bahwa wakaf adalah, perbuatan hukum seseorang atau kelompok orang atau badan hukum yang memisahkan sebagian dari benda miliknya dan melembagakannya untuk selama-lamanya, guna kepentingan ibadat atau keperluan umum lainnya sesuai dengan ajaran Islam. Dalam pengertian lain, sebagaimana disebutkan dalam UU RI No 41 tahun 2004 tentang wakaf, mendefinisikan wakaf sebagai berikut: "Wakaf adalah perbuatan hukum wakif untuk memisahkan dan atau menyerahkan sebagian harta benda miliknya, untuk dimanfaatkan selamanya atau untuk jangka waktu tertentu, sesuai dengan kepentingannya guna keperluan ibadah dan atau kesejahteraan umum menurut syari'ah. Walau definisi wakaf berbeda antara satu dengan yang lain, akan tetapi definisi tersebut nampaknya berpegang pada prinsip bahwa benda wakaf, pada hakikatnya adalah pengekalan dari manfaat benda wakaf itu. Namun demikian, dari beberapa definisi dan keterangan di atas, dapatlah ditarik suatu kesimpulan bahwa wakaf itu meliputi beberapa aspek sebagai berikut: Harta benda itu milik yang sempurna; Harta benda itu zatnya bersifat kekal dan tidak habis dalam sekali atau dua kali pakai; Harta benda tersebut dilepaskan kepemilikannya oleh pemiliknya; Harta benda yang dilepaskan kepemilikannya tersebut, adalah milik Allah dalam arti tidak dapat dihibahkan, diwariskan atau diperjualbelikan; dan Manfaat dari harta benda tersebut untuk kepentingan umum yang sesuai dengan ajaran Islam.

Wakaf merupakan salah satu lembaga hukum Islam yang Pelaksanaanya di Indonesia mengalami perkembangan. Dalam KHI wakaf adalah perbuatan hukum seseorang atau kelompok orang atau badan hukum yang memisahkan sebagian dari benda miliknya dan melembagakannya untuk selama-lamanya guna kepentingan ibadat atau keperluan umum lainnya sesuai dengan ajaran Islam. 


\section{POTENSI WAKAF UANG KOTA METRO}

Dalam Peraturan Badan Wakaf Indonesia No. 01 tahun 2009 tentang Pedoman Pengelolaan dan Pengembangan Harta Benda Wakaf Bergerak berupa Uang, sertifikat dapat diberikan kepada wakafi yang telah mewakafkan uangnya paling sedikit Rp 1.000.000 (satu juta rupiah) dengan menyertakan asal-usul uang dan identitas lengkap wa-qif nya.

Jumlah umat Islam yang terbesar di dunia terutama di Indonesia merupaka aset terbesar untuk penghimpunan dan pengembangan wakaf uang. Jika wakaf uang dapat diimplementasikan maka akan terdapat dana potensial yang dapat dipergunakan bagi kemaslahatan umat. Berdasarkan asumsi Cholil Nafis", jika 20 juta umat Islam Indonesia mau mengumpulkan wakaf uang senilai Rp 100 ribu setiap bulan, maka dana yang terkumpul berjumlah Rp 24 triliun setiap tahun. Jika 50 juta orang yang berwakaf, maka setiap tahun akan terkumpul dana wakaf sebesar Rp 60 triliun. Jika saja terdapat 1 juta umat Muslim yang mewakafkan dananya sebesar Rp 100.000 per bulan, maka akan diperoleh pengumpulan dana wakaf sebesar Rp 100 miliar setiap bulannya (Rp 1,2 triliun per tahun).

Menurut Mustafa Edwin Nasution $^{5}$ tentang potensi wakaf di Indonesia dengan jumlah umat Muslim yang dermawan diperkirakan sebesar 10 juta jiwa dengan rata-rata penghasilan Rp. 500.000 hingga Rp. 10.000.000, maka paling tidak akan terkumpul dana sekitar 3 triliun per tahun dari dana wakaf. Kita melihat penduduk Kota Metro yang mayoritas umat Islam dari jumlah penduduk 165.000 jiwa dengan rata-rat penghasilan Rp.400.000 hingga Rp.1000.000, akan terkumpul dana sekitar 1,5 miliar per tahun dari dana wakaf, dari dana itulah nanti kita bisa gunakan untuk membantu masyarakat Kota Metro yang belum berkecukupan.

Wakaf merupakan ibadah yang berdimensi ganda, selain untuk menggapai keridhaan serta pahala dari Allah, wakaf merupakan ibadah yang berdimensi sosial. Dalam sejarah Islam, wakaf banyak digunakan untuk kepentingan sosial. Wujud kepentingan sosial tersebut dapat berupa pemberdayaan masyarakat, jaminan sosial, pendidikan, kesehatan, dan lain-lain.

Dalam manajemen modern saat ini, wakaf diintegrasikan dengan berbagai sistem modern yang telah ada, terutama terkait dengan wakaf uang saat ini tengah digencarkan di Indonesia. Berdasarkan UU No. 41 tahun 2004, penerimaan dan pengelolaan wakaf uang dapat April 2009

${ }^{4}$ Cholil Nafis, ,Wakaf Uang Untuk Jaminan Sosial , Jurnal Al-Awqaf, Vol. II, Nomor 2,

${ }^{5}$ Mustafa Edwin Nasution, 'Wakaf Tunai dan Sektor Volunteer', dalam Mustafa Edwin Nasution dan Uswatun Hasanah (ed), Wakaf Tunai Inovasi Finansial Islam (Jakarta: PSTTI UI, 2006), 43-44. 
diintegrasikan dengan lembaga keuangan syariah. Dalam wakaf uang, wakif tidak boleh langsung menyerahkan mauquf yang berupa uang kepada na-zir, tetapi harus melalui LKS, yang disebut sebagai LKS Penerima Wakaf Uang (PWU).

Dalam sistem pengelolaan wakaf uang tidak banyak berbeda dengan wakaf tanah atau bangunan, na-zir bertugas untuk menginvestasikan sesuai syariah dengan satu syarat: nilai nominal uang yang diinvestasikan tidak boleh berkurang. Sedangkan hasil investasi dialokasikan untuk upah na-zir (maksimal 10\%) dan kesejahteraan masyarakat (minimal 90\%) ${ }^{6}$

Saat ini yang tengah berjalan adalah kerjasama na-zir dengan perbankan syariah. Ini tercermin dari Keputusan Menteri Agama RI No. 92-96 tahun 2008 yang menunjuk lima bank syariah untuk bermitra dengan na-zir dalam soal wakaf uang. Kelima bank tersebut adalah Bank Muamalat Indonesia, Bank Syariah Mandiri, BNI Syariah, DKI Syariah dan Bank Syariah Mega Indonesia. Namun tidak menutup kemungkinan, ke depan pengembangan wakaf uang juga bisa dipadukan dengan instrumen lembaga keuangan syariah non-bank.

Dalam pasal 34 amandemen UUD 1945 dikatakan, ,Bahwa negara mengembangkan sistem jaminan sosial bagi seluruh rakyat dan memberdayakan masyarakat yang lemah dan tidak mampu sesuai dengan martabat kemanusiaan'. Berdasarkan amandemen UUD 1945 tersebut secara eksplisit bahwa Negara harus mampu memberdayakan masyarakat. Terminologi pemberdayaan adalah membantu masyarakat agar mereka mampu menjadi mandiri dalam mensejahterakan dirinya sendiri. Wakaf uang sebagai suatu gerakan baru dalam dunia perwakafan terutama di Indonesia mampu mengambil peranan yang signifikan dalam merancang program-program pemberdayaan masyarakat. Tugas memberdayakan masyarakat bukanlah tugas pemerintah semata, tetapi merupakan tanggung jawab setiap elemen masyarakat, yang, karenanya, harus turut serta dalam memberdayakan masyarakat. Program pemberdayaan masyarakat dapat dilakukan dengan sistem perwakafan, hal ini sesuai dengan UU No. 41 tahun 2004 tentang wakaf yang telah mengamanatkan Badan Wakaf Indonesia agar mengelola harta benda wakaf yang berskala nasional dan internasional. Sifat utama perwakafan mengharuskan kekal dan abadi pokok hartanya, lalu dikelola dan hasilnya disalurkan sesuai dengan peruntukannya sangat sesuai dan selaras dengan program sistem jaminan sosial atau asuransi. Dalam perwakafan, pihak wakif dapat menentukan peruntukan hasil pengelolaan harta wakaf.

${ }^{6}$ UU No. 41 tahun 2004, pasal 12. 
Dalam ketentuan undang-undang terdapat dua model wakaf uang, yaitu wakaf uang untuk jangka waktu tertentu dan wakaf uang untuk selamanya. Wakaf uang jangka waktu tertentu haruslah diinvestasikan ke produk perbankan agar lebih aman dan memudahkan pihak wakaf dalam menerima uangnya kembali pada saat jatuh tempo. Sedangkan wakaf uang untuk selamanya, pihak na-zir memiliki otoritas penuh untuk mengelola dan mengembangkan uang wakaf untuk mencapai tujuan wakafnya. Bila kegiatan investasi menggunakan dana penghimpunan wakaf, maka atas keuntungan bersih usaha hasil investasi ini (yaitu pendapatan kotor dikurangi dengan biaya operasional), akan dibagikan sesuai dengan ketentuan undang-undang wakaf yaitu $90 \%$ keuntungan akan diperuntukkan untuk tujuan wakaf (mauquf 'alaih) dan 10\% untuk penerimaan pengelola atau na-zir.

\section{WAKAF PADA PEMBERDAYAAN MASYARAKAT KOTA METRO}

Dalam kehidupan kaum Muslim, Islam sangat menekankan pentingnya keadilan sosial. Dalam beberapa ayat, Allah SWT selalu menekankan betapa pentingnya keadilan10, karena keadilan akan membimbing pada ketakwaan (QS Al-Ma'idah: 8), ketakwaan akan membawa pada kesejahteraan (QS Al-A'raf: 96). Sebaliknya, ketidakadilan akan membawa kesesatan (QS Al-Qasas\}: 50) dan akan menjauhkan manusia dari rahmat Tuhan. Intisari ajaran Islam yang terkandung dalam Al-Qur'an mengibarkan panji-panji amanah, egaliter, prinsip emansipatoris dan keadilan sosial.

Para pengelola lembaga wakaf di Indonesia harus peduli dalam mewujudkan masyarakat yang adil dan sejahtera. Lembaga wakaf terutama yang memiliki basis organisasi massa ataupun badan hukum, dapat menjadi salah satu sub-sistem alternatif di masyarakat yang saling bahu-membahu dengan sub-sistem masyarakat lainnya dalam menyelesaikan persoalan bangsa. Wakaf sebagai salah satu pranata keagamaan dalam Islam yang memiliki keterkaitan langsung secara fungsional dengan upaya pemecahan masalah-masalah sosial dan kemanusiaan seperti pengentasan kemiskinan, peningkatan sumber daya manusia dan pemberdayaan masyarakat khususnya Kota Metro.

Sistem perwakafan dapat dilakukan sebagai alternatif yang mungkin dalam merealisasikan jaminan sosial. Hal ini seiring dengan telah disahkannya UU No. 41 tahun 2004 tentang wakaf, yang telah mengamanatkan kepada Badan Wakaf Indonesia agar mengelola harta benda yang berskala nasional dan internasional. Secara mendasar, perwakafan mengharuskan pokok harta tersebut kekal dan abadi, sehingga dikelola dan hasilnya diperuntukkan bagi program jaminan sosial termasuk bagi pemberdayaan masyarakat. 
Dalam ketentuan undang-undang terdapat dua model wakaf uang, yaitu wakaf uang untuk jangka waktu tertentu dan wakaf uang untuk selamanya ${ }^{7}$. Wakaf uang untuk jangka waktu tertentu haruslah diinvestasikan ke produk perbankan agar lebih aman dan memudahkan pihak wakaf dalam menerima uangnya kembali pada saat jatuh tempo. Sedangkan wakaf uang untuk selamanya, pihak na>z\}ir memiliki wewenang penuh untuk mengelola dan mengembangkan uang wakaf untuk mencapai tujuan program wakaf yang dilakukan.

Hasil pengelolaan dana wakaf dapat diperuntukkan bagi pemberdayaan masyarakat Kota Metro ${ }^{8}$, seperti pemberdayaan pendidikan, kesehatan, sosial ataupun ekonomi. Bentuk pemberdayaan pendidikan misalnya dengan mendirikan sekolah gratis dengan kualitas baik atau bantuan bagi kesejahteraan guru. Sedangkan pemberdayaan masyarakat dapat berupa pemeriksaan kesehatan dan pengobatan gratis bagi masyarakat kurang mampu, bantuan gizi ibu hamil, serta persalinan gratis. Pemberdayaan sosial dapat berupa pelatihan kerja dan kewirausahaan. Pemberdayaan ekonomi berupa bantuan dana bergulir.

\section{E. WAKAF UANG PANDANGAN ULAMA}

Sistem wakaf merupakan konsep yang tidak secara jelas dan tegas disebutkan dalam al Qur" an, dan hadits. Berbeda dengan zakat yang secara jelas disebutkan didalam Al Qur'an.

Imam al Bukhari (wafat tahun $2526 \mathrm{H}$ ) mengungkapkan bahwa Imam Az Zuhri (wafat tahun $124 \mathrm{H}$ ) berpendapat dinar dan dirham (keduanya mata uang yang berlaku ditimur tengah) boleh diwakafkan. Yang berarti membolehkan wakaf dalam bentuk uang (wakaf tunai).

Mahzab Hanafi juga membolehkan wakaf tunai sebagai pengecualian, atas dasar istihsan bi al „urfi (adat kebiasaan), karena sudah banyak dilakukan masyarakat. Cara melakukan wakaf tunai menurut mahzab Hanafi adalah menjadikannya modal usaha dengan cara mudharabah sedang keuntungannya disedekahkan kepada pihak wakaf.

Menurut al Bakri, mahzab Syafi'I tidak membolehkan wakaf tunai, karena dinar dan dirham (uang) akan lenyap ketika dibayarkan sehingga tidak ada lagi wujudnya. Namun sebagian pengikut mahzab syafi'i membolehkan wakaf tunai.

Jadi pengikut mahdzab Syafi'I ada dua pendapat, ada yang membolehkan wakaf tunai, ada yang tidak membolehkan. Pendapat ulama mengenai obyek wakaf memperlihatkan bahwa syarat-syarat benda

${ }^{7}$ Peraturan Pemerintah Nomor 42 tahun 2006, Pasal 48 ayat 3: Dalam hal LKS-PWU menerima wakaf uang untuk jangka waktu tertentu, maka na-zir hanya dapat melakukan pengelolaan dan pengembangan harta benda wakaf uang pada LKS-PWU dimaksud

${ }^{8}$ M. Nur Rianto Al Arif, ,Pemberdayaan Masyarakat Berbasis Wakaf Uange, Jurnal AsySyir'ah, Vol. 44, No. II, 2010, 825. 
wakaf ( harus benda, bermanfaat, tidak sekali pakai, tidak haram zatnya dan harus milik wakif secara sempurna ). Wakaf tunai tidak didukung oleh hadis secara khusus, dan menggunakan ayat-ayat al-Qur'an dan hadis bersifat umum. Oleh karena itu, penentuan syarat-syarat obyek wakaf termasuk wilayah ijtihadi.

\section{F. PENUTUP}

Dalam ketentuan undang-undang terdapat dua model wakaf uang, yaitu wakaf uang untuk jangka waktu tertentu dan wakaf uang untuk selamanya. Wakaf uang jangka waktu tertentu haruslah diinvestasikan ke produk perbankan agar lebih aman dan memudahkan pihak wakaf dalam menerima uangnya kembali pada saat jatuh tempo. Sedangkan wakaf uang untuk selamanya, pihak na-zir memiliki otoritas penuh untuk mengelola dan mengembangkan uang wakaf untuk mencapai tujuan wakafnya. Bila kegiatan investasi menggunakan dana penghimpunan wakaf, maka atas keuntungan bersih usaha hasil investasi ini (yaitu pendapatan kotor dikurangi dengan biaya operasional), akan dibagikan sesuai dengan ketentuan undang-undang wakaf yaitu 90\% keuntungan akan diperuntukkan untuk tujuan wakaf (mauquf 'alaih) dan 10\% untuk penerimaan pengelola atau na-zir. Wakaf uang yang dikelola dapat memberikan efek pengganda dalam perekonomian Kota Metro, baik hasil investasi wakaf uang tersebut diberikan dalam bentuk bantuan sektor ekonomi maupun sektor non ekonomi. Hasil ini secara langsung dan tidak langsung akan mampu memberikan pengaruh signifikan dalam mengentaskan kemiskinan.

Gerakan Metro Wakaf adalah gerakan sukarela yang mengajak semua warga kampus untuk bergerak bersama. Wakaf Tunai adalah mekanisme wakaf untuk membangun dana abadi ummat. Dengan berwakaf sekali tapi pahala tanpa henti. Berbeda dengan sedekah yang sekali habis, wakaf tunai dapat dikembangkan ke unit usaha dan hasilnya untuk kepentingan ummat. Selama ini wakaf tunai sudah dilakukan oleh dosen dan karyawan IAIN Metro secara sukarela. Kami melakukan wakaf tunai dengan menyisihkan uang gaji bulanan sesuai kerelaan. Kami optimis bahwa gerakan sukarela ini akan semakin banyak mengajak orang lain untuk terlibat tanpa paksaan. Untuk itu sosialisasi wakaf uang harus terus dikampanyekan oleh semua pihak khususnya di Kampus IAI Agus Salim Metro. 


\section{Daftar Pustaka}

Al Arif, M. Nur Rianto. ,Pemberdayaan Masyarakat Berbasis Wakaf Uang. Jurnal Asy-Syir'ah, Vol. 44, No. II, (2010).

--------. ,Efek Multiplier Wakaf Uang dan Pengaruhnya terhadap Program Pengentasan Kemiskinan.' Jurnal Asy-Syir'ah, Vol. 46, No. I, (2012).

-------. ,Potensi Wakaf Uang dan Dampaknya Terhadap Perekonomian. Jurnal Dialog, No. 70, Tahun XXXIII, (2010).

-------. Teori Makroekonomi Islam: Konsep, Teori dan Analisis. Bandung: CV Alfabeta, 2010.

Ali, Mohammad Daud. Sistem Ekonomi Islam Zakat dan Wakaf. Jakarta: UI Press, 1988.

--------. ,Strategi Pengembangan Wakaf Tunai di Indonesia. Direktorat Pemberdayaan Wakaf, Jakarta: Dirjen Bimas Islam, 2006.

Faizin, Hamam. ,Mengembangkan Wakaf Produktif di Indonesia. Jurnal Dialog, No. 70, Tahun XXXIII, (2010).

Kasdi, Abdurrahman. ,Pemberdayaan Wakaf Produktif Untuk Keadilan Sosial dan Kesejahteraan Umat (Optimalisasi Potensi Wakaf Produktif di Indonesia). ' Jurnal Asy-Syir'ah, Vol. 44, No. II, (2010).

Nafis, M. Cholil. ,Wakaf Uang Untuk Jaminan Sosial. Jurnal Al-Awqaf, Vol II, No. 2, (2009).

Nasution, Mustafa E. dan Uswatun Hasanah, ed. Wakaf Tunai Inovasi Finansial Islam. Jakarta: PSTTI-UI, 2006.

Rahmawati, Yuke. ,Efektivitas Mekanisme Funding Wakaf Uang di Perbankan Syariah.' Jurnal Dialog, No. 70, Tahun XXXIII, (2010). 